\title{
Validasi Program Remaja "STOP" (Sadar, Tolong, dan Perangi) Bullying untuk Mengurangi Intensi Perilaku Bullying pada Siswa SMP
}

\author{
Deni Tri Anggraeni ${ }^{1}$, Amitya Kumara², E Muhana Sofiati Utami ${ }^{3}$ \\ Fakultas Psikologi, Universitas Gadjah Mada
}

\begin{abstract}
Bullying cases in Indonesia happens among middle school students. Some literatures mention that bullying behavior in school is supported by peers. This study aims to validate the program Remaja "STOP" (Sadar, Tolong, dan Perangi) Bullying to prevent and reduce the bullying intention students through peers. Peer facilitators is 19 students who never involve bullying behavor, brave to defend and support the victims, have a good communication skills and self confidence. While the subject of this research is 32 students that getting middle score on Intention Bullying Behavior Scale. Validation test is used before conducted the research. This study used untreated control group design with pretest and double postest as design experiment. The collected data was analyzed with anava mixed design showed that Remaja "STOP" (Sadar, Tolong, dan Perangi) Bullying program is valid to improve a fasilitator peer's antibullying knowledge and presentation skill. Also, this program is valid tu decrease the intention of bullying among middle school students.
\end{abstract}

Keywords: bullying, peers, adolescent, program Remaja "STOP"(Sadar, Tolong, dan Perangi) Bullying

Abstrak. Penelitian ini bertujuan untuk menguji validasi pogram Remaja "STOP" (Sadar, Tolong, dan Perangi) Bullying dalam meningkatkan pengetahuan antibullying dan ketrampilan presentasi pada fasilitator sebaya. Fasilitator sebaya kemudian menyampaikan materi bullying kepada subjek penelitian agar intensi perilaku bullying tersebut menurun. Program Remaja "STOP" Bullying melatih 9 orang siswa SMP sebagai fasilitator sebaya yang menyampaikan materi terkait bullying kepada teman yang terlibat perilaku bullying di sekolah. Pengambilan data menggunakan Skala Intensi Perilaku Bullying. Subjek penelitian adalah siswa kelas VIII SMP Negeri di Yogyakarta dengan skor intensi perilaku bullying sedang (16 siswa sebagai kelompok kontrol \& 16 siswa sebagai kelompok eksperimen). Penelitian ini menggunakan Untreated Control Group Design with Pre-test and double Post-test sebagai desain eksperimen. Data yang diperoleh dianalisis dengan Anava Mixed Design menunjukkan hasil bahwa program Remaja "STOP" (Sadar, Tolong, dan Perangi) Bullying valid meningkatkan pengetahuan antibullying dan ketrampilan presentasi pada fasilitator sebaya. Selain itu, program ini valid untuk mengurangi intensi perilaku bullying pada siswa SMP.

Kata kunci: bullying, teman sebaya, remaja, program Remaja "STOP" (Sadar, Tolong, dan Perangi) Bullying.

\footnotetext{
${ }^{1}$ Korespondensi mengenai isi artikel ini dapat dilakukan melalui : denitri.anggraeni@mail.ugm.ac.id

2 Atau melalui muhana@ugm.ac.id
} 
Bullying yang terjadi pada siswa di sekolah merupakan masalah utama kesehatan masyarakat nasional maupun internasional (Nansel, Craig, Overpeck, Saluja, \& Ruan, 2004; Hamburger, Basile \& Vivilo, 2011). Data dari U.S Department of Education (dalam Lessne \& Cidade, 2015) menyebutkan sejumlah siswa berusia 1218 tahun menjadi korban bully di sekolah dan media sosial, dan 1 dari 4 siswa (22\%) mengaku menjadi korban bully di sekolah selama 1 tahun terakhir. Penelitian yang dilakukan di Inggris didapatkan hasil bahwa $75 \%$ dari 4700 anak usia 11 - 16 tahun pernah mengalami tindakan bullying secara fisik (Glover, Gough, Johnson, \& Cartwright, 2000). Hasil penelitian yang dilakukan Rigby $(2007,2012)$ di Australia pada 38.000 anak dengan rentang usia 7-16 tahun yaitu lebih dari $30 \%$ subjek penelitian mengakui bahwa mereka pernah menjadi korban bully di sekolah.

Berdasarkan data Praktek Kerja Profesi Psikologi yang dilakukan oleh Desvianti (2015) pada siswa SMP Negeri di kota Yogyakarta, ditemukan hasil bahwa terdapat perilaku bullying di sekolah. Bullying yang umum terjadi adalah ejekan, hinaan, dipermalukan di depan umum, menjadi bahan gurauan, dibentak, dijegal, diikat di kursi, dan mengambil barang milik teman. Sementara itu, hasil preeliminary yang dilakukan peneliti pada tanggal 2-23 Februari 2016 kepada 198 siswa di dua SMP Negeri Yogyakarta yaitu terdapat beberapa peristiwa bullying yang terjadi di sekolah. 198 siswa SMP Negeri tersebut diberi Skala Kecenderungan Bullying yang disusun oleh Wahyuni (2010) berdasarkan teori ciri-ciri perilaku bullying dari Olweus (1993). Kecenderungan perilaku bullying yang banyak terjadi berdasarkan hasil preeliminary antara lain menjadikan bahan tertawaan/menyoraki $(13,3 \%)$, menyebar kejelekan teman $(9,7 \%)$, mengejek $(8,75 \%)$, menyebar hal yang tidak benar tentang seseorang $(8 \%)$, memukul $(6,88 \%)$, dan melakukan ejekan, hinaan, atau ancaman pada media sosial $(4,14 \%)$.

Olweus (1993) mendefinisikan bullying dengan menggunakan situasi di mana siswa yang ditindas atau menjadi korban bully memperoleh perlakuan negatif secara berulang dan terus menerus oleh satu atau beberapa siswa lain. Maksud dari perlakuan negatif menurut Olweus (1993) adalah ketika seseorang sengaja untuk menimbulkan ketidaknyamanan atau luka kepada orang lain. Bullying mempunyai karakteristik yang utama yaitu 1) adanya perilaku agresif, 2) terjadi secara berulang dan terus-menerus, dan 3) terdapat kekuatan yang tidak seimbang antara pelaku dengan korban (Olweus, dalam Elinoff Chafouleas, \& Sassu, 2004), 4) bullying biasanya terorganisir, sistematis, dan tersembunyi, 5) biasanya terjadi dalam periode waktu yang lama, 6) korban bullying mengalami rasa sakit secara fisik, emosi, dan psikologis, 7) semua bentuk perilaku bullying memiliki dimensi emosi atau psikologis (Sullivan, Cleary, \& Sullivan, 2005).

Bullying sering dikaitkan dengan kemarahan, agresi, kekerasan, hiperaktifitas dan masalah eksternal yang nantinya dapat mengarah pada kriminalitas dan memiliki efek negatif baik dalam jangka pendek ataupun jangka panjang. Dampak bullying bagi siswa (Rigby, 2007) yaitu meningkatkan level kecemasan siswa, hilangnya rasa percaya diri serta self-esteem, meningkatkan symptoms psikosomatik seperti sakit kepala, sakit perut, dan luka pada mulut/bibir, self-harm dan mempunyai pemikiran suicidal, merasa dikucilkan dari sekolah.

Perilaku bullying merupakan siklus yang dalam lingkaran siklus tersebut dipengaruhi oleh faktor motivasional atau intensi (Ulfah, 2015). Intensi merupakan 
faktor utama dalam theory of planned behavior yang dapat secara akurat memprediski kecenderungan perilaku dari individu. Teori planned behavior ini berdasar asumsi bahwa setiap manusia merupakan makhluk rasional yang mampu menggunakan informasi secara sistematis yang memungkinkan bagi dirinya sendiri. Individu akan memikirkan implikasi dari tindakan mereka sebelum mereka memutuskan untuk melakukan atau tidak melakukan perilaku tertentu (Ajzen, 2005) Jika asumsi tersebut dikaitkan dengan perilaku bullying, maka faktor penentu yang terpenting dari bullying adalah intensinya. Intensi didefinisikan sebagai faktor motivasional yang dapat memengaruhi perilaku. Intensi mengindikasikan seberapa keras individu mencoba, usaha individu dalam merencanakan dan mengusahakan munculnya suatu perilaku (Ajzen,1991). Intensi memiliki 3 aspek, yaitu attitude toward behavior, subjective norm, dan perceived behavior control (Ajzen, 2005).

Menurut Bandura (1986), intensi merupakan suatu kebulatan tekad untuk melakukan aktivitas tertentu atau menghasilkan suatu keadaan tertentu di masa depan. Intensi (dan perilaku) adalah fungsi dari tiga faktor penentu, yaitu individu dalam lingkungannya, refleksi pengaruh sosial, dan kontrol perilaku yang (Ajzen, 2005). Armitage dan Conner (2001) menambahkan bahwa ketiga faktor penentu tersebut dalam intensi merupakan proses kognitif dari terjadinya suatu perilaku. Struktur kognitif individu menjadi dasar dalam proses mental terhadap suatu perilaku tertentu.

Salah satu contoh bahwa lingkungan memengaruhi intensi dan perilaku seseorang yaitu adanya penelitian Tumon (2014) yang menunjukkan sebanyak 61,7 \% subjek penelitian mengaku bahwa lingkungan sekolah merupakan lingkungan pertemanan yang saling memengaruhi. Selain itu, sebanyak 17\% subjek penelitian mengaku melakukan tindakan bullying karena mengikuti teman dan sebanyak 53\% mengaku agar diterima oleh kelompok sebayanya. Hal tersebut memperlihatkan dua hal yaitu: 1) perilaku bullying yang ada di sekolah tidak bisa terlepas dari pengaruh teman sebaya, 2) adanya persetujuan dari lingkungan terhadap bullying memengaruhi subjective norms dalam menilai dan niat (intensi) untuk melakukan tindakan bullying.

Penelitian ini menggunakan program Remaja "STOP" (Sadar, Tolong, dan Perangi) Bullying untuk melatih fasilitator sebaya agar terampil dalam menyampaikan materi presentasi mengenai bullying pada subjek penelitian. Karena akan menyampaikan materi kepada teman sebayanya, fasilitator perlu dilatih mengenai cara melakukan presentasi dan penyampaian materi bullying yang baik. Secara garis besar, Program Remaja "STOP" (Sadar, Tolong, dan Perangi) Bullying memiliki 3 tujuan utama, yaitu: 1) membuat fasilitator sadar, --yang secara harfiah dapat diartikan mengerti dan memahami keadaan tertentu--, bahwa bullying mempunyai dampak yang kurang baik, 2) dengan kesadaran akan dampak bullying tersebut, diharapkan fasilitator sebaya dapat menolong (tolong) dan memberikan bantuan berupa pengetahuan kepada korban, pelaku, atau teman-teman di lingkungan sekolah terhadap kejadian bullying, 3) sehingga fasilitator sebaya dan teman-teman di lingkungan sekolah dapat bersama-sama memerangi (perangi) bullying di sekolah agar perilaku bullying di sekolah dapat stop (berhenti). Terdapat dua tahap dalam penelitian ini yaitu, 1) trainer melatih fasilitator sebaya mengenai pengetahuan bullying dan ketrampilan presentasi berdasarkan komunikasi verbal dan nonverbal, dan 2) fasilitator sebaya setelah memperoleh pelatihan 
mempresentasikan materi bullying kepada subjek penelitian dengan harapan perilaku bullying yang ada di sekolah menjadi berkurang.

Penelitian ini menggunakan teman sebaya sebagai perantara untuk mengurangi kejadian bullying di sekolah karena perilaku awal bullying sangat dipengaruhi oleh teman sebaya pada jenjang SMP (Cunningham, 2007; Adilla, 2009), selain itu jika bullying terjadi pada remaja awal, biasanya akan diperparah di jenjang sekolah selanjutnya (Sullivan, Cleary \& Sullivan, 2005). Teman sebaya dalam program anti-bullying bertugas memberi informasi untuk mengembangkan pengetahuan, sikap dan tindakan siswa dalam rangka memerangi bullying melalui proses komunikasi, informasi, dan edukasi. Ajzen (dalam Losey, 2009) menjelaskan faktor sosial dan kognitif memengaruhi perilaku yang dipilih seseorang. Seseorang dapat mengambil peran dalam situasi bullying mempertimbangkan kerugian dan keuntungan yang diperolehnya dalam kerterlibatan peristiwa bullying. Pertimbangan kerugian dan keuntungan yang diperoleh seseorang tersebut tentunya dipengaruhi oleh informasi yang dimiliki tiap individu. Dalam penelitian Salmivalli (dalam Dake, Price, dan Telljohann, 2003) menyebutkan bahwa perlunya pelatihan kepada pendidik teman sebaya agar dapat mengambil tindakan dalam memerangi bullying.

Program Remaja "STOP" (Sadar, Tolong, dan Perangi) Bullying dalam penelitian ini merupakan suatu rangkaian kegiatan pelatihan, di mana kegiatan pelatihan yang dilakukan ditulis dalam sebuah modul. Modul Remaja "STOP" Bullying ini disusun dengan dua tema utama dan dua proses pelatihan yaitu, 1) Tema bullying yang disusun berdasarkan modifikasi dari materi Bully Buster Program (BBP) (Newman-Carlson dan
Horne, 2004) dan ketrampilan presentasi berdasarkan komunikasi verbal dan nonverbal (Book, Albrecht, Atkin, Bettinghaus, et al. (1980); Hargie (2011)), 2) Melatih fasilitator sebaya supaya terampil dalam mempresentasikan materi bullying dan fasilitator sebaya yang telah dilatih mempresentasikan pengetahuan bullying kepada subjek penelitian. Peneliti menggunakan metode presentasi karena biasa digunakan untuk menyampaikan informasi atau pelatihan kepada audiens.

Peneliti menyusun modul dengan terlebih dahulu menentukan metode pembelajaran, teori yang akan digunakan, serta media pendukung lainnya. Kemudian peneliti melakukan uji validasi pada Modul Remaja "STOP" Bullying sebelum digunakan untuk melatih fasilitator sebaya. Menurut Russel (1974) dalam pembuatan sebuah modul, setelah menentukan teori dan menyusun media yang akan digunakan, peneliti juga perlu untuk menguji reliabilitas dan validitas modul untuk mengetahui efektivitas modul yang dibuat. Jika modul (setelah digunakan) mampu mencapai tujuan serta menghasilkan dampak yang diinginkan, maka modul tersebut dapat disimpulkan memenuhi syarat pembuatan modul dan dapat diimplementasikan. Proses validasi modul Remaja "STOP" Bullying dilakukan melalui beberapa langkah. Sugiyono (2015) menyebutkan bahwa proses validasi modul dilakukan dengan pengujian internal dan eksternal. Pengujian internal dapat dilakukan beberapa kali hingga ditemukan rancangan yang dianggap sempurna. Pada penelitian ini, pengujian internal dilakukan dengan meminta penilaian kepada beberapa professional judger terkait kesesuaian antara isi, materi, dan tujuan modul. Sedangkan pengujian eksternal dilakukan dengan pengujian lapangan yang dilakukan dengan mencobakan modul tersebut pada situasi nyata, yaitu 
kepada subjek yang memenuhi kriteria inklusi. Pada penelitian ini, pengujian eksternal dilakukan dengan melakukan pelatihan kepada subjek terkait modul yang sudah disusun dan dinilai oleh professional judger.

Modul pelatihan yang dibuat dalam penelitian ini menggunakan pendekatan observational learning (pembelajaran melaui pengamatan). Penelitian Groenendijk, Janssen, Rijlaarsdam, \& Bergh (2011) menunjukkan bahwa metode observational learning dapat berpengaruh kepada performansi, proses dan motivasi seseorang. Metode tersebut meningkatkan hasil kreativitas khususnya pada bidang seni visual. Hasil penelitian ini menguatkan bahwa observational learning dapat digunakan untuk mempelajari sesuatu yang baru dalam bentuk pengetahuan maupun ketrampilan.

Berdasarkan uraian di atas, tujuan dari penelitian ini adalah untuk melakukan validasi modul Remaja "STOP" Bullying yang disusun untuk memberikan pengetahuan mengenai teori bullying dan ketrampilan presentasi materi antibullying pada fasilitator sebaya. Program Remaja "STOP" Bullying digunakan fasilitator sebaya untuk menyampaikan materi mengenai bullying pada teman sebaya, dengan harapan dapat menurunkan intensi perilaku bullying pada siswa dengan skor intensi perilaku bullying yang sedang.

Manfaat penelitian ini adalah untuk menyusun suatu instrumen untuk mencegah dan mengurangi perilaku bullying di sekolah dengan memanfaatkan teman sebaya sebagai agen sekolah. Selain itu, penelitian ini bermanfaat dalam pengembangan teori mengenai fasilitator sebaya sebagai agen sekolah, khususnya dalam pencegahan dan mengurangi tindakan bullying di sekolah. Hipotesis yang diajukan dalam penelitian ini adalah modul Remaja "STOP" (Sadar, Tolong, dan Perangi) Bullying valid untuk mengurangi intensi perilaku bullying pada siswa SMP.

\section{Metode}

Penelitian ini menggunakan desain eksperimen kuasi, yaitu untreated control group design with pretest and double posttest (Sadish, Cook, Campbell, 2002), dengan kelompok kontrol dan kelompok eksperimen. Pengukuran dilakukan dengan pretest dan postest pada kedua kelompok. Terdapat dua subjek dalam penelitian ini, yaitu fasilitator sebaya berjumlah 9 orang, serta subjek penelitian berjumlah 16 orang pada kelompok kontrol dan kelompok eksperimen. Pada penelitian ini, instrumen yang digunakan dibagi menjadi 2, yaitu untuk fasilitator sebaya dan subjek penelitian. Instrumen yang digunakan untuk fasilitator sebaya yaitu Modul Remaja "STOP" (Sadar, Tolong, dan Perangi) Bullying, Panduan Observasi Ketrampilan Presentasi dan Pengetahuan bullying, sedangkan instrumen yang digunakan untuk subjek penelitian yaitu Skala Intensi Perilaku Bullying. Analisis data dalam penelitian ini menggunakan teknik analisis anov amixed design dengan tujuan untuk menguji perubahan perbedaan skor antara skor pretest ke skor posttest Skala Intensi Perilaku Bullying antara kelompok eksperimen dan kelompok kontrol.

\section{Hasil}

Uji validasi pada modul Remaja "STOP" Bullying menunjukkan hasil bahwa nilai validasi modul berada pada rentang 0,690,91, di mana masing-masing aspek pada masing-masing sesi memiliki nilai mendekati 1,00 yang berarti bahwa secara redaksional, bahasa, waktu, permainan yang digunakan, prosedur dan instruksi, 
lembar kerja serta metode yang digunakan pada Modul Remaja "STOP" Bullying ini memiliki nilai validitas isi yang baik.

Rata-rata skor intensi perilaku bullying pada hasil pretest kelompok kontrol yaitu 128.63 lebih tinggi dibandingkan dengan rata-rata skor intensi perilaku bullying kelompok eksperimen, yaitu 127.62. Setelah diberikan perlakuan, terlihat bahwa ratarata skor posttest intensi perilaku bullying pada kelompok eksperimen berkurang dan lebih rendah yaitu 86.00 dibandingkan dengan kelompok kontrol yaitu 118.81. Kurang lebihnya 3 minggu setelah pelaksanaan posttest, peneliti melakukan follow up untuk skor intensi bullying. Berdasarkan hasil follow up, kelompok eksperimen mempunyai rata-rata skor intensi perilaku bullying 85.06, sedangkan kelompok kontrol mempunyai rata-rata skor 117.63 .

Hasil uji homogenitas untuk mengetahui homogenitas kovarian skor intensi perilaku bullying pada kelompok eksperimen dan kelompok kontrol berdasar nilai pretests, posttest, dan followup. Kelompok eksperimen dan kelompok kontrol memenuhi asumsi homogenitas dengan nilai signifikansi $\mathrm{p}>$ 0.05. hal tersebut menunjukkan bahwa data intensi perilaku bullying kedua kelompok adalah homogen.

Hasil uji hipotesis menunjukkan nilai $F$ sebesar 92.299 dan $p<0,001$ artinya terdapat perbedaan intensi perilaku bullying pada pretest, posttest, dan follow up. Dari baris time * subjek menunjukkan nilai F sebesar 33.585 dan $p<0.001$. hal ini mengindikasikan adanya interaksi antara waktu (pretest, posttest, dan follow up) dan kelompok (eksperimen-kontrol). Adanya interaksi ini menunjukkan bahwa terdapat perubahan skor intensi perilaku bullying pada kondisi pretest, posttest, dan follow up antara kelompok kontrol dan kelompok eksperimen. Data tersebut menunjukkan bahwa pemberian program pelatihan Remaja "STOP" Bullying secara signifikan dapat mengurangi perilaku intensi bullying siswa.

Hasil analisis uji lanjutan membuktikan bahwa presentasi materi antibullying dengan fasilitator sebaya dapat menurunkan intensi perilaku bullying secara signifikan pada kelompok eksperimen. Sumbangan efektif presentasi dengan fasilitator teman sebaya pada kelompok eksperimen berdasar nilai partial eta squared sebesar $0.850(\mathrm{p}<0.05)$. presentasi dengan fasilitator teman sebaya yang dilakukan pada kelompok eksperimen memberikan kontribusi sebesar $85 \%$, sedangkan kelompok kontrol mengalami penurunan sebesar $26.5 \%$ (sig.0.011, $\quad \mathrm{p}<0.05$,) terhadap perubahan intensi perilaku bullying. Meskipun kelompok kontrol mengalami penurunan, berdasarkan hasil t-test yang dilakukan peneliti menunjukkan bahwa penurunan yang terjadi antara kelompok eksperimen dan kelompok sebaya mempunyai perbedaan rata-rata intensi bullying yang signifikan dengan nilai $\mathrm{t}=6.210(\mathrm{sig}<0.01)$. Dengan nilai mean intensi perilaku bullying kelompok eksperimen lebih rendah dibanding kelompok kontrol.

\section{Diskusi}

Penelitian ini bertujuan untuk menguji validitas modul pelatihan Remaja "STOP" (Sadar, Tolong, dan Perangi) Bullying untuk mengurangi intensi perilaku bullying pada siswa SMP dengan pendekatan observational learning. Validasi yang dilakukan dalam penelitian ini menggunakan validitas isi yang dilakukan oleh beberapa ahli. Berdasarkan hasil penilaian oleh 8 orang ahli diperoleh nilai Aiken $\mathrm{V}$ pada rentang 0,687-0,812, di mana masing-masing sesi memiliki nilai mendekati 1,00 yang berarti bahwa secara isi, Modul Remaja "STOP" Bullying 
memiliki nilai validitas isi yang baik. Azwar (2015) menyatakan bahwa aitem yang berada pada kisaran 0.666 dapat dianggap memuaskan. Hal ini berarti adanya kesesuaian antara sesi modul dengan tujuan pelatihan serta pendekatan dalam observational learning. Selanjutnya modul Remaja "STOP" Bullying dapat digunakan pada subjek penelitian.

Pretest skala intensi perilaku bullying diberikan kepada kelompok eksperimen dan kelompok kontrol menunjukkan rerata skor intensi perilaku bullying yang tidak jauh berbeda. Pada pengukuran postest setelah dilakukan presentasi, kelompok eksperimen menunjukkan penurunan yang signifikan. Hal tersebut ditandai dengan nilai $\mathrm{F}$ sebesar 82.430 dan $\mathrm{p}<0,05$. Kelompok eksperimen diketahui mengalami penurunan skor intensi perilaku bullying yang signifikan setelah mengikuti presentasi dengan fasilitator sebaya. Penurunan skor dapat dilihat dari selisih rata-rata (MD) skor pretest ke posttest sebesar 41.625 dengan $\mathrm{p}<0.05$. Pada kelompok kontrol juga mengalami perubahan skor inteni perilaku bullying yang signifikan, di mana selisih rata-rata (MD) skor pretest ke posttest sebesar 9.812 dengan $\mathrm{p}<0.05$.

Pengukuran selanjutnya dilaksanakan setelah dua minggu pelatihan selesai. Hasil analisis data follow up pada kelompok eksperimen menunjukkan bahwa tidak terdapat perubahan skor intensi perilaku bullying yang signifikan pada pengukuran posttest ke follow up. Hasil ini mengindikasikan bahwa pengaruh intervensi yang dilakukan dapat bertahan hingga follow up dilaksanakan. Faktor yang memengaruhi hasil tersebut adalah sumbangan efektif pelatihan sebesar 85\%. Sementara itu, pada kelompok kontrol meskipun mengalami penurunan skor intensi perilaku bullying yang siginikan, sumbangan efektif yang diberikan hanya sebesar 26,5\%. Hasil tersebut sejalan dengan penelitian yang dilakukan oleh Erhard (1999) mengenai pencegahan penggunakan alkohol dan obat-obatan pada siswa kelas 8 di Israel yaitu, presentasi yang diberikan fasilitator sebaya memberikan pengaruh pada remaja untuk mengurangi konsumsi alkohol dan obat-obatan. Selain itu, pada penelitian tersebut remaja juga lebih memilih fasilitator sebaya sebagai tempat untuk saling bertukar informasi dan berbagi mengenai hal sensitif dibanding dengan guru. Dengan hasil yang demikian, dapat dikatakan bahwa hipotesis yang diajukan dalam penelitian ini dapat diterima, yang mana Program Remaja "STOP" (Sadar Tolong dan Perangi) Bullying valid untuk mengurangi intensi perilaku bullying siswa SMP. Kelompok eksperimen yang memperoleh presentasi dengan materi antibullying oleh fasilitator sebaya menunjukkan penurunan skor intensi perilaku bullying.

Penelitian sebelumnya terkait dengan intensi menunjukkan adanya pengaruh antara pengetahuan dengan intensi individu untuk menunjukkan atau melakukan suatu perilaku. Penelitian yang dilakukan oleh Gusti, Isyandi, Bahri, \& Afandi (2015) menemukan bahwa pengetahuan mengenai sampah berkelanjutan berkontribusi positif dengan sikap terhadap pengelolaan sampah berkelanjutan pada siswa SD. Demikian halnya dengan penelitian yang dilakukan oleh Jalani, Rani, Isahak, Aris, \& Roslan (2016) menemukan bahwa adanya pengetahuan pada siswa SMP mengenai kanker serviks berpengaruh pada intensi remaja untuk melakukan vaksin. Dengan adanya pengetahuan yang dimiliki keinginan remaja untuk melakukan vaksin meningkat sebanyak dua kali lipat lebih tinggi daripada remaja yang tidak mempunyai pengetahuan mengenai kanker serviks. Ajzen, Joyce, Sheikch \& Cote (2011) menambahkan bahwa yang 
menentukan intensi dan perilaku seseorang adalah penyampaian informasi (keyakinan) yang mengaitkan ketertarikan seseorang akan suatu hal sehingga menunjukkan perilaku positif atau negatif, dan sebagai faktor pengontrol yang dapat memudahkan atau menghalangi perilaku mereka.

Faktor yang dinilai penting pada presentasi yang dilakukan oleh fasilitator sebaya adalah kemampuan trainer dalam menyampaikan dan menyajikan materi agar dapat mencapai tujuan penelitian. Kemampuan trainer membuat fasilitator sebaya dapat memperoleh pengetahuan mengenai bullying, pengetahuan ketrampilan presentasi serta semakin terampil dalam melakukan presentasi dengan materi antibullying dihadapan subjek penelitian. Fasilitator sebaya yang mengikuti pelatihan melewati proses belajar sesuai dengan metode observational learning. Terdapat beberapa proses dalam obseravtional learning, proses yang pertama yaitu attention. Pada proses ini, atensi dipengaruhi oleh nilai fungsional yang dirasakan dari aktivitas individu lain yang menjadi model. Atensi yang diberikan oleh fasilitator teman sebaya dipengaruhi oleh ketertarikannya terhadap materi dan ketrampilan yang akan mereka pelajari. Hal tersebut terlihat dari antusiasme mereka selama proses pelatihan berlangsung. Antusiasme ditunjukkan dengan menyimak dan memperhatikan dengan detail apa yang trainer sampaikan, mencatat materi yang disampaikan trainer, serta membuat beberapa pertanyaan terkait dengan materi yang disampaikan. Selain itu, trainer memiliki kemampuan presentasi yang sesuai dengan karakter remaja sehingga dapat meningkatkan perhatian calon fasilitator dalam mempelajari materi bullying dan ketrampilan presentasi dengan teknik komunikasi verbal dan nonverbal. Trainer menyampaikan materi dengan contoh- contoh yang dekat dengan kehidupan sehari-hari peserta, melibatkan peserta dalam memberikan contoh bullying, menggunakan tayangan power point yang sangat baik dan media audiovisual seperti video tayangan bullying. Bandura (1986) menyebutkan bahwa model yang diamati merupakan hal yang penting untuk mendapatkan proses atensi pada observational learning.

Keberhasilan tahap selanjutnya, yaitu tahap retention dan production, didukung oleh kemampuan yang dimiliki fasilitator sebaya dalam menyimpan dan mengembangkan ketrampilan yang telah diperoleh. Fasilitator sebaya yang terpilih merupakan rekomendasi dari guru dan teman-teman atas prestasi yang dimiliki baik secara akademik maupun non akademik. Sehingga informasi dan amatan yang mereka peroleh selama pelatihan dapat diingat dan disimpan untuk selanjutnya mereka praktekan dihadapan subjek dengan baik. Tahapan motivasi dapat berhasil dilakukan karena adanya simulasi yang dilakukan pada saat pelatihan. Pada proses simulasi, masingmasing peserta memperoleh feedback yang baik dari trainer. Selain itu, proses simulasi disesuaikan dengan apa yang telah dipelajari pada sesi materi pelatihan. Sehingga, pada saat melakukan presentasi di depan subjek, fasilitator sebaya dapat melakukan dengan baik pula. Selama proses intervensi berlangsung, fasilitator teman sebaya mengalami peningkatan dalam pengetahuan bullying dan kemampuan mereka dalam presentasi dengan teknik komunikasi verbal maupun non verbal. Sementara itu, subjek penelitian juga mengalami peningkatan pada pengetahuan mereka terkait bullying dan mengalami penurunan dalam intensi perilaku bullying.

Skala Intensi Perilaku Bullying yang disusun menggunakan rating scale dari 1 hingga 5, semakin menuju angka 5, maka 
intensi perilaku bullying yang dimiliki subjek semakin tinggi. Begitu juga sebaliknya, semakin mendekati angka 1 , maka intensi perilaku bullying yang subjek miliki semakin rendah. Sebelum diberi perlakuan, subjek pada kelompok eksperimen memiliki skor intensi perilaku bullying kategori sedang, yang mana skor begerak mendekati angka 5. Setelah perlakuan diberikan, skor intensi perilaku bullying subjek semakin mendekati angka 1, yang berarti intensi perilaku bullying semakin rendah. Subjek penelitian memperoleh intervensi berupa presentasi dengan fasilitator teman sebaya. Proses presentasi yang disajikan memengaruhi intensi perilaku bullying. Hal tersebut disebabkan adanya dinamika psikologis yang kemudian memengaruhi intensi perilaku bullying.

Intensi memiliki 3 aspek (Ajzen, 2006), yaitu attitude toward behavior, subjective norm, dan perceived behavior control. Pertama, aspek attitude toward behavior, merupakan keyakinan terhadap perilaku dan evaluasi hasil. Behavioral beliefs ditentukan oleh keyakinan yang paling menonjol pada diri individu terhadap perilaku tertentu (Ajzen, 2006). Pada proses presentasi yang dilakukan oleh fasilitator teman sebaya, terjadi pertukaran informasi dan pendapat mengenai bullying. Subjek menjadi tahu apa itu bullying, apa saja bentuk bullying, bagaimana akibat yang dihasilkan, dan bagaimana seharusnya bersikap terhadap bullying yang terjadi di sekitar mereka. Perolehan pengetahuan mengenai bullying ini menjadi bahan pertimbangan subjek untuk membentuk sikap terhadap bullying. Pada sesi akhir presentasi, keempat kelompok beranggapan bahwa bullying mempunyai dampak yang buruk baik bagi pelaku atau korban yang harus segera di"STOP". Berdasar kesepakatan tersebut, subjek telah membentuk sikap negatif pada bullying.
Kedua, aspek subjective norm, yang merupakan aspek intensi terkait persepsi individu terhadap tuntutan dari lingkungan sosialnya untuk perilaku tertentu. Norma subjektif adalah persepsi individu mengenai harapan orang-orang yang penting bagi dirinya baik perorangan ataupun kelompok untuk menampilkan perilaku tertentu atau tidak (Ajzen, 2006). Presentasi yang dilakukan oleh fasilitator sebaya kemudian membentuk sikap terhadap perilaku bullying pada subjek pelatihan. Masing-masing subjek penelitian sepakat bahwa bullying yang ada di sekolah merupakan masalah sosial yang harus di'STOP'. Selain itu, keempat kelompok sepakat bahwa tindakan bullying merupakan tindakan yang tidak membuat individu keren dimata temanteman yang lain. Hal tersebut menunjukkan bahwa ada tuntutan lingkungan sosial untuk men'STOP' tindakan bullying. Kemudian, aspek ketiga yaitu perceived behavior control yang merupakan faktor pemberi gambaran mengenai persepsi individu terkait kemudahan atau kesulitan individu dalam menampilkan perilaku dan diasumsikan sebagai refleksi dari pengalaman yang telah terjadi sebelumnya serta hambatanhambatan yang diantisipasi (Ajzen, 2006). Dalam proses presentasi, diketahui bahwa bagi subjek penelitian, bullying merupakan hal yang menyenangkan serta lucu, sehingga bagi mereka, bullying merupakan hal yang dianggap biasa. Dalam kondisi tersebut, dapat dianggap sulit ketika subjek akan menunjukkan perilaku melawan bullying. Presentasi yang dilakukan memberikan gambaran tindakan yang sebaiknya subjek lakukan ketika melihat ataupun mengalami bullying. Kesepakatan teman-teman dalam kelompok presentasi tersebut membantu menumbuhkan keyakinan bahwa mereka dapat bersama-sama men"STOP" dan mengatasi bullying. 
Berdasar uraian di atas, telah terjadi dinamika selama proses presentasi, yang mana presentasi oleh fasilitator teman sebaya menghasilkan penilaian negative terhadap bullying, tuntutan dari teman sebaya untuk tidak melakukan bullying, dan keyakinan untuk dapat bersama-sama mengatasi bullying. Hal tersebut menyebabkan terjadinya penurunan intensi perilaku bullying pada subjek kelompok eksperimen. Selain itu, penurunan intensi perilaku bullying juga dipengaruhi oleh modalitas yang dimiliki oleh fasilitator sebaya, antara lain: prestasi akademik yang memadai, pengalaman berorganisasi, dan kesesuaian metode dalam penyampaian materi bullying.

Keterbatasan penelitian ini adalah adanya penurunan skor intensi perilaku bullying pada kelompok kontrol. Kelemahan yang dimiliki pada eksperimen kuasi adalah adanya ancaman pada validitas internal yang merupakan perkiraan mengenai hubungan sebab akibat (Shadish, Cook, Campbell, dalam Hastjarjo, 2011). Di mana ancaman validitas internal pada kelompok eksperimen salah satunya adalah sejarah. Sejarah merupakan kejadian yang berlangsung pada saat bersamaan dengan perlakuan. Di mana terdapat persitiwa yang terjadi antara pretest dan posttest yang dapat menimbulkan hasil yang diperoleh bukan karena perlakuan yang diberikan (Shadish, Cook, Campbell, 2002).

Selain itu, peneliti belum melakukan validasi isi terkait prosedur dalam modul mengenai presentasi yang dilakukan oleh fasilitator sebaya kepada subjek penelitian. Hal tersebut penting, mengingat pelaksanaan presentasi oleh fasilitator sebaya kepada subjek merupakan rangkaian yang harus dilakukan.

\section{Kesimpulan}

Berdasar hasil analisis dan diskusi yang telah disampaikan, dapat ditarik kesimpulan modul Remaja "STOP" (Sadar, Tolong,dan Perangi) Bullying dapat meningkatkan pengetahuan fasilitator sebaya mengenai bullying serta meningkatkan ketrampilan presentasi dalam menyampaikan pengetahuan yang dimiliki. Modul Remaja "STOP" (Sadar, Tolong, dan Perangi) Bullying yang melatih fasilitator sebaya untuk melakukan presentasi antibullying dapat menurunkan intensi perilaku bullying pada siswa SMP N di Yogyakarta. Presentasi yang dilakukan fasilitator sebaya memberikan kontribusi sebesar $85 \%$ terhadap penurunan intensi perilaku bullying.

Berdasarkan hasil penelitian dan pembahasan yang dilakukan, saran dari peneliti untuk penelitian selanjutnya adalah peneliti selanjutnya diharapkan dapat mengaplikasikan penelitian ini dengan karakteristik subjek yang berbeda dengan bentuk atau kejadian bullying yang berbeda pula. Selain itu, untuk penelitian selanjutnya diharapkan mempertimbangkan untuk memberikan pencegahan dan materi khusus terkait cyberbully yang pada saat penelitian hal tersebut banyak ditemui di lapangan. Untuk mengurangi dampak dari extraneous variable berupa sejarah, penelitian selanjutnya diharapkan dapat melakukan kontrol terhadap kelompok kontrol. Kontrol dapat dilakukan dengan memastikan tidak ada intervensi atau pemberian pengetahuan yang berhubungan dengan tema penelitian dari pihak luar.

\section{Kepustakaan}

Adilla, N. (2009). Pengaruh kontrol sosial terhadap perilaku bullying pelajar di sekolah menengah pertama. Jurnal Kriminologi Indonesia, 5(1), 56-66. 
Ajzen, I. (1991). The theory of planned behavior. Organizational behavior and human decison processes, 50, 179-211.

Ajzen, I. (2005). Attitudes, personality, and behavior: second edition. MiltonKeynes, England: Open University Press / McGraw-Hill.

Ajzen, I. (2006). Constructing a TPB questionnaire: Conceptual and methodological considerations. Diunduh dari: http://people. umass. edu/aizen/ pada tanggal 19 Juli 2016.

Ajzen, I., Joyce, N., Sheikh, S., \& Cote, N.G. (2011). Knowledge and the prediction of behavior: The role of information accuracy in the theory of planned behavior. Basic and applied social psychology. (33). 101-117. doi: 10.1080/01973533.2011.568834

Armitage, S., \& Conner, M. (2001). Efficacy the theory of planned behavior: A meta-analytic review. British Journal of Social Psychology, 40, 471-499.

Azwar, S. (2015). Reliabilitas dan validitas: Edisi 4. Yogyakarta: Pustaka Pelajar

Bandura, A. (1986). Social foundation of thought and action. Engelwood Cliffs, NJ, US: Prentice-Hall.

Book, C. L., Albrecht, T. L., Atkin, C., Bettinghaus, E. P., et al. (1980). Human communication: Principles, contexts, and skills. New York: St. Martin's Press.

Cunningham, N. J. (2007). Level of bonding to school and perception of to school environments by bullies, victims, and bully victims. Journal of early adolescence. 27(4), 457-475.

Dake, J. A., Price, J. H., \& Telljohann, S. K. (2003). The nature and extent of bullying at school. Journal School Health, 73(5), 173 - 180.

Desvianti, E. (2015). Laporan kelompok praktek kerja profesi psikologi. Tidak diterbitkan. Yogyakarta: Fakultas Psikologi, Universitas Gadjah Mada
Elinoff, M. J., Chafouleas, S. M., \& Sassu, K. A. (2004). Bullying: considerations for defining and intervening in school settings. Psychology in the School-Wiley Periodical. 41(8). doi: 10.1002/pits.20045

Glover, D., Gough, G., Johnson, M., \& Cartwright, N. (2000). Bullying in 25 secondary schools: Incidence, impact, and intervention. Educational Research, 42(2), 141-156.

Groenendijk, T., Janssen, T., Rijlaarsdam, G., \& Bergh, V. (2011). The effect of observatiomal learning on students' performance, processes, and motivation in two creative domains. British Journal of Educational Psychology. 1-26. doi: 10.1111/j.20448279.2011.02052.x

Gusti, A., Isyandi, B., Bahri, S., \& Afandi, D. (2015). Hubungan pengetahuan, sikap dan intensi perilaku pengelolaan sampah berkelanjutan pada siswa sekolah dasar di kota Padang. Dinamika lingkungan Indonesia, 100-107.

Hamburger, M. E., Basile, K. C., \& Vivolo, A. M. (2011). Measuring bullying victimization, perpetration, and bystander ecperiences: A compendium assessment tools. Atlanta, GA: Centers for Disease Control and Prevention, National Center for Injury Prevention and Control.

Hargie, O. (2011). Skilled interpersonal communication: research, theory, and practice $5^{\text {th }}$ Edition. London: Routledge, Taylor \& Francis Group.

Hastjarjo, T. D. (2011). Kausalitas menurut tradisi Donald Campbell. Buletin Psikologi, 19(1), 1-5.

Jalani, F. F. M., Rani, M. D. M., Isahak, I., Aris, M. S. M., \& Roslan N. (2016). Knowledge, attitude, and practice of human papillomavirus (HPV) vaccination among secondary school studets in rural areas of negeri 
sembilan, malaysia. International journal of collaborative research on internal medicine \& public health. 8(6). 56-70.

Lessne, D., \& Cidade, D. (2015). Students reports of bullying and cyberbullying: Result from 2013 school crime supplement to the national crime victimization. Washington D.C: United States Department of Education.

Losey, R. A. (2009). An evaluation of the olweus bullying preventions program's effectiveness in a high school setting. Dissertation. Doctorate of Counselor Education, University of Cincinnati

Nansel, T. R., Craig, W., Overpeck, M. D., Saluja, G., \& Ruan, W. J. (2004). Cross-national consistency in the relationship between bullying behaviors and psychosocial adjustment. Archives of Pediatrics and Adolescent Medicine. 158(8). 730-736.

Newman-Carlson, D., \& Horne, A. M. (2004). Bully busters: A psychoeducational intervention for reducing bullying behavior in middle school students. Journal of Counseling and Development, 82, 25926

Olweus, D. (1993). Bullying at school: What we know and what we can do. Oxford: Blackwell Publishing.

Rigby, K. (2007). Bullying in schools: And what to do about it. Victoria: ACER Press

Rigby, K. (2012). Bullying interventions in schools : Six basic approaches. West Sussex: Wiley-Blackwell A John Wiley \& Sons, Ltd., Publication
Ruseel, J. D., \& Johanningsmeier, K.A. (1981). Improving competence through modular instruction. Toronto: Kendall/Hunt Publishing Company

Shadish, W. R., Cook, T. D., \& Campbell D. T. (2002). Experimental and quasiexperimental design for generalized causal inference. Houghton Mifflin Company

Sugiyono. (2015). Metode penelitian pendidikan (pendekatan kuantitatif, kualitatif dan RED). Bandung: CV. Alfabeta

Sullivan, K., Cleary, M., \& Sullivan, G. (2005). Bullying in secondary schools: What it looks like and how to manage it. London: Paul Chapman Publishing, A SAGE Publications Company

Tumon, M. B. A. (2014). Studi deskriptif bullying pada remaja. Jurnal Ilmiah Mahasiswa Universitas Surabaya. 3(1). 1-17.

Ulfah, S. F. (2015). Pengaruh program "sahabat perangi bullying" (SHARING) guna menurunkan intensi perilaku bullying. Tesis. Yogyakarta: Magister Profesi Psikologi Universitas Gadjah Mada

Wahyuni, S. (2010). Hubungan antara persepsi terhadap pola asuh otoriter orangtua \& kemampuan berempati dengan kecenderungan berperilaku bullying pada remaja. Tesis. Yogyakarta: Magister Psikologi Universitas Gadjah Mada 